\title{
Influence of parameters and location of the tumble inlet porton air charging in the diesel cylinder
}

\author{
Besarion Meskhi ${ }^{1}$, Boris Golev ${ }^{1,2}$, Victor Efros ${ }^{1,2}$, Dmitriy Rudoy ${ }^{1}$, Anastasiya \\ Olshevskaya $^{1, *}$, Viktor Zhurba ${ }^{l}$, Yevgeniy Chayka ${ }^{1}$ \\ ${ }^{1}$ Don State Technical University, sq. Gagarina, 1, 344010, Rostov-on-Don, Russia \\ ${ }^{2}$ Public Joint-Stock Company Rostselmash, 2, MenzhinskogoStr, 344029, Rostov-on-Don, Russia
}

\begin{abstract}
The calculation of the actual working cycle processes allows to determine with satisfactory accuracy the value of the main parameters of the newly developed engine for any given conditions of its operation, to assess the impact of individual factors on the processes and the performance of the cycle as a whole. Thus establish character of change of pressure and temperature in each process, define the sizes of the engine, and also solve questions of increase of its reliability taking into account the received settlement thermal and dynamic loadings. Pre-intake begins at the time of opening the inlet and ends at the time of arrival of the piston in the TDC. The mixture or air does not enter the cylinder during preheating, as the volume of the cylinder decreases. However, the pre-opening of the intake valve allows you to create a sufficient cross-section to the beginning of the receipt of fresh charge in the cylinder and, therefore, leads to an improvement in the filling of the cylinders. In addition, due to the delay in closing the exhaust valve, the purge of the combustion chamber from residual gases is improved.
\end{abstract}

\section{Introduction}

In modern high-speed engines, the opening of the intake valve occurs on average for $10-30^{\circ}$ before the arrival of the piston in the upper dead center (TDC).

The main intake starts at (TDC) and ends at the lower dead center (NMT). The pressure in the cylinder during the main intake continuously changes, due to the corresponding change in the flow section of the valve and the speed of the piston. The average gas pressure in the cylinder during the intake is less than atmospheric; therefore, energy is consumed to implement the process. The duration of the main intake is $180^{\circ}$ of the crankshaft rotation angle[1,2,5].

The delay of the inlet is necessary for recharging the cylinder with a fresh charge. In this case, the high-speed head, inertial and wave phenomena in the intake system are used. Reloading of cylinders depends on the choice of valve timing, length of the intake tract, the

*Corresponding author: oav.donstu@gmail.com 
speed of the crankshaft. At rated engine operation with correctly selected parameters of the intake system, the recharge is $10-15 \%$.

The duration of the delay is $30-85^{\circ}$ after (NMT). The pressure and temperature of the environment. In engines without supercharging, air enters the cylinder from the atmosphere, and when calculating the operating cycle, the ambient pressure is assumed to be

$p_{o}=0,1 \mathrm{MPa}$, and the temperature $T_{o}=293^{\circ} \mathrm{K}[3,6]$.

equal

\section{Materials and Methods}

The location of the inlet ports (IP) in relation to the axis of the cylinder and their profile largely determine the structure of the rotational motion of the air charge in the cylinder of the diesel engine. IP are conventionally divided into single-function (tumble ports), providing only filling of the cylinder with air and two-function (tangential, swirl), promoting the air swirl motion at the inlet stroke in the cylinder and the combustion chamber, effectively influencing the quality of the processes of mixture formation and combustion in a diesel engine $[4,7]$.

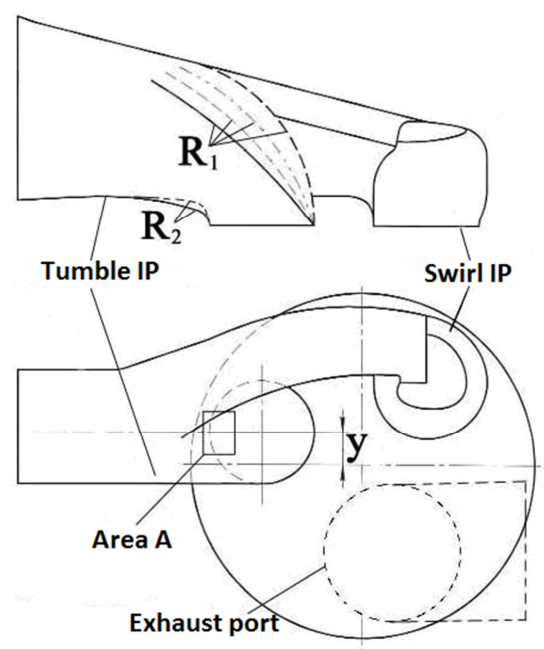

Fig. 1 IP scheme

In order to determine the effect of the parameters and location of the IP on the gasdynamic characteristics of the air charge in the cylinder, numerical study of the IP presented in Fig. 1 was carried out. The object of the study was the cylinder head, which includes two inlet ports (tumble and screw with throat diameters $\mathrm{d}_{\mathrm{IP}}=32 \mathrm{~mm}$ ) and an exhaust one $\left(\mathrm{d}_{\mathrm{EP}}=37 \mathrm{~mm}\right)$ meant for the diesel engine.

The mathematical model and methods of the numerical study have been created in the CFD program. The error in determining the air flow Q $(\mathrm{kg} / \mathrm{h})$ through the IP is less than $2 \%$. The numerical studies were carried out at valve lift $\mathrm{h}_{\mathrm{v}}=4,6,8,10,11,12 \mathrm{~mm}$ with a pressure drop $\Delta \mathrm{P}=6000 \mathrm{~Pa}$ in the port. The variable parameters characterizing the position of the tumble IP are the distance $y$, and its profile - the radius of the upper - $\mathrm{R}_{1}$ and lower $R_{2}$ elements of the port. The range of variation of $y$ was $0 \ldots 9.5 \mathrm{~mm}, \mathrm{R}_{1}-135 \ldots 180 \mathrm{~mm}, \mathrm{R}_{2}$ $5 \ldots 7.5 \mathrm{~mm}$. The profile of the swirl port and its location in relation to the axis of the cylinder remained unchanged[8,9]. 
The study of the air flow in the cylinder made it possible to conclude that the air charge released from the valve slit of the tumble port is evenly distributed over the cylinder volume (Fig. 2.1). At the same time, the obvious absence of the angular momentum in relation to the axis of the cylinder additionally confirmed the ports tumble functionality. In its turn, the swirl port forms a pronounced rotational motion in the cylinder (Fig. 2.2).

An important feature is observed during the confunction of the considered IP. The air flow coming out of the valve slit of the tumble IP positively affects the intensification of rotational motion, as a result of which the angular momentum of the $\mathrm{M}_{\mathrm{TIP}}$ is on the average $10 \%$ higher than the sum of the moments of the tumble IP and the swirl IP. In addition, attention should be paid to the flow pattern located in B zone of Fig. 2.3, where the air flows formed by the tumble and swirl IP, interacting with each other, are getting reshaped and acquire the direction tangent to the cylinder wall, which should be considered an essential advantage.[10].
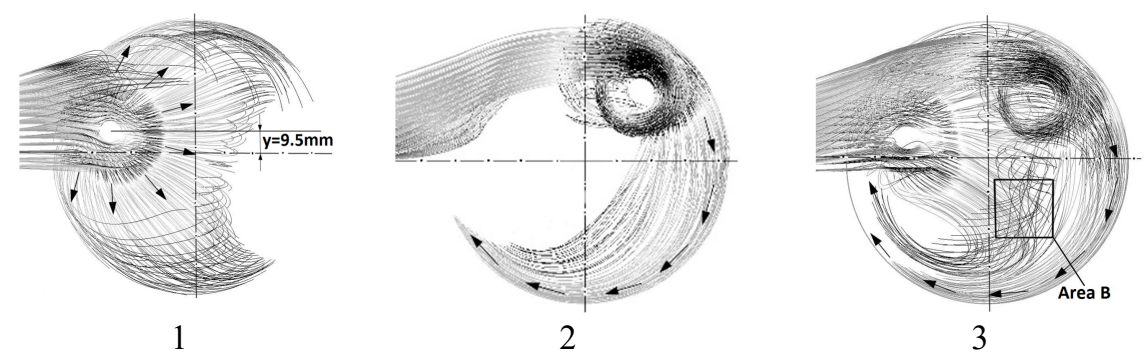

Fig. 2 Pattern of the air flows in the cylinder $\left(R_{I}=180 \mathrm{~mm}, R_{2}=5 \mathrm{~mm}\right)$ :

1-Tumble IP; 2 - Swirl IP; 3 - Both IP

The part of air entering the cylinder through each IP in the initial version $(y=9.5 \mathrm{~mm}$, $\mathrm{R}_{1}=180 \mathrm{~mm}, \mathrm{R}_{2}=5 \mathrm{~mm}$ ), falling on the tumble and swirl IP, is 56 and $44 \%$ respectively. The distance y expectedly does not significantly affect the air flow through the IP (Fig. 3), which is important to know when placing both ports themselves as well as the nozzle, glow plug, cooling fins, and other structural elements in the cylinder head of the designed diesel engine.

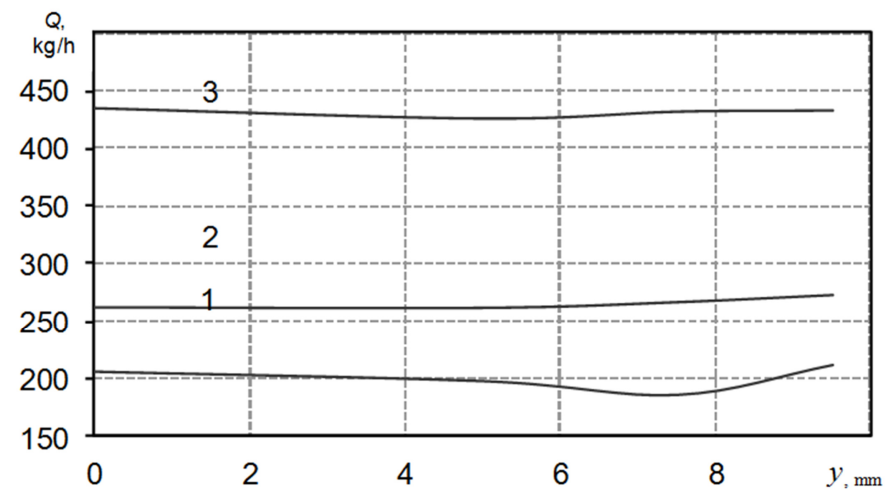

Fig. 3The influence of y on air flow $\mathrm{Q} \quad\left(\mathrm{h}=12 \mathrm{mmandR}_{1}=180 \mathrm{~mm}\right)$ 1 - Swirl IP; 2 - Tumble IP; 3 - Both IP 
It should be noted that with a change in the distance y from 9.5 to $0 \mathrm{~mm}$ the intensity of the total swirl motion is estimated by $36 \%$. The location of the tumble IP, which allows providing rotational motion in the recommended range for a considered diesel, is achieved at $\mathrm{y}=5 \ldots 6.3 \mathrm{~mm}$.

As expected, the shape of the upper element of the tumble IP has a greater impact on air flow. The reduction of $\mathrm{R}_{1}$ radius from $180 \mathrm{~mm}$ to $135 \mathrm{~mm}$ caused an increase in the total air flow through the ports by $18 \mathrm{~kg} / \mathrm{h}$ (Fig. 3). In this case, the air flow through the swirl port decreases from 44 to $42 \%$, and the total swirl - by $19 \%$, which is the result of an increase in the part of air flow going through the tumble IP by reducing its resistance $[11,12]$.

It was established that in the valve slit of the initial IP variant, the flow is interrupted, causing local turbulence of the air charge (Fig. 5.1), reducing the effective flow area in this zone and ultimately negatively affecting the IP flow rate. The combined increase in $\mathrm{R}_{1}$ and $\mathrm{R}_{2}$ made it possible to avoid flow stall in the valve slit aria (Fig. 5.2). In addition, a change

In $\mathrm{R}_{2}$ from 5.0 to $7.5 \mathrm{~mm}$ significantly caused an increase in $\mathrm{Q}$ by another $4 \%$. As a

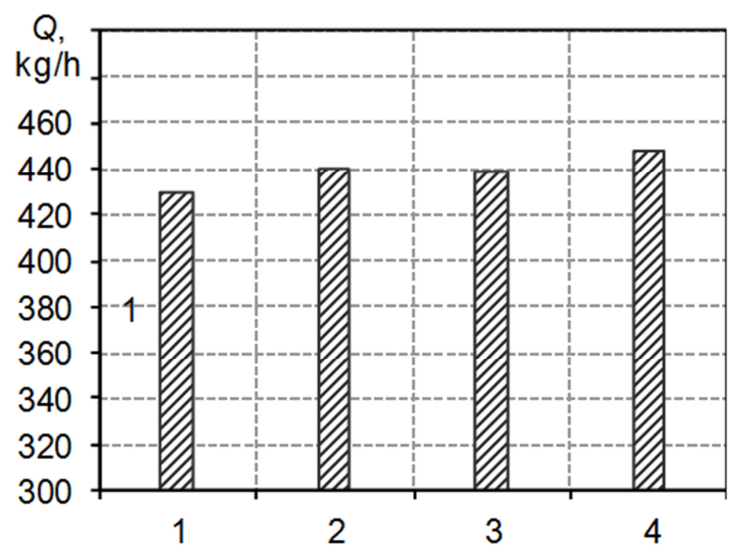

Fig. 4. The effect of $R_{1}$ values (1 - $180 \mathrm{~mm}, 2-165 \mathrm{~mm}, 3-150 \mathrm{~mm}, 4-135 \mathrm{~mm}$,) on the air flow $Q$ during the joint operation of the IP $\left(h_{\mathrm{V}}=12 \mathrm{~mm}\right.$ and $\left.\mathrm{y}=9.5 \mathrm{~mm}\right)$.

result, at maximum valve lift, compared with the initial port profile, the growth of $\mathrm{Q}$ reached

$35 \mathrm{~kg} / \mathrm{h}(7.5 \%)$, and swirl motion slightly decreased to $4,5 \%$
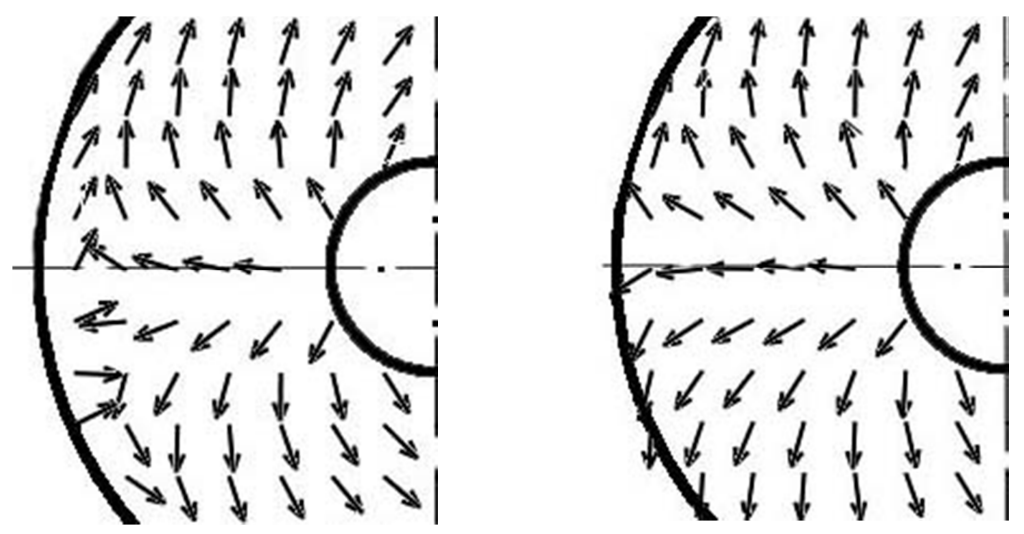
Fig. 5. The distribution of velocity vectors in the valve slit (Area A, Fig. 1.) of the tumble IP $(y=9.5 \mathrm{~mm}): 1-\mathrm{R}_{1}=180 \mathrm{~mm} ; \mathrm{R}_{2}=5.0 \mathrm{~mm} ; 2-\mathrm{R}_{1}=135 \mathrm{~mm} ; \mathrm{R}_{2}=7.5 \mathrm{~mm}$

The change in gas-dynamic parameters for the initial and modified profiles of the tumble port is shown in Fig. 6. A steady increase in air flow is observed over the entire range of valve lifts, while at the same time, a decrease in the momentum of the air

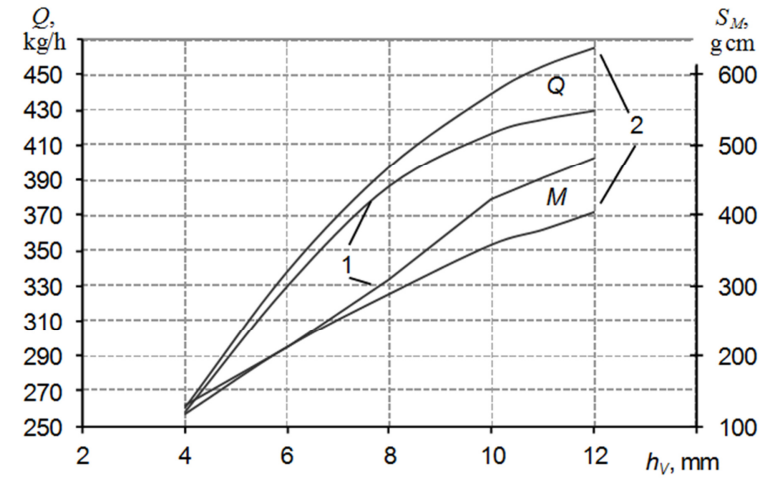

Fig. 6. Change in the gas-dynamic parameters of IP for various valve lifts $(y=9.5 \mathrm{~mm}): 1-$ Initial IP; 2 - Modified IP

charge is observed only in the range $\mathrm{h}_{\mathrm{V}}=7 \ldots 12 \mathrm{~mm}$. Thus, changing the profile of the tumble port simultaneously improves both the flow characteristics of the IP and provides the necessary intensity of rotational motion in the cylinder for a diesel engine.

\section{Discussion}

Pressure and temperature of residual gases. Before starting the intake process, the volume $\mathrm{Vc}$ of the combustion chamber always contains a certain amount of residual gases. The pressure of residual gases depends on the number and location of the valves, the resistance of the inlet and outlet paths, valve timing, engine speed and load, the method of pressurization and other factors.

Pressure and temperature at the end of the inlet. Under the pressure of the end of the intake RA understand the average pressure for the intake process. Since the intake system has a resistance, the pressure PA for engines without supercharging is always lower, and engines with supercharged PA above atmospheric [3,4,5].

The resistance of the intake system depends on many factors:

- the length of the pipes, their cross section;

- from presence in inlet system of knees, roughnesses of walls of pipelines;

- from the resistances of the air cleaner, carburetor.

With the correct selection of the length of the intake pipeline, taking into account the speed of the engine, inertial supercharging and cylinder recharging are achieved. As the engine crankshaft speed increases, the RA pressure decreases due to an increase in the suction system resistance due to an increase in the charge velocity[7,9]. 
The temperature of the gas in the engine cylinder at the end of the intake depends on the temperature and mass of the fresh charge, the temperature and mass of the gases remaining in the cylinder from the previous cycle, and the degree of charge heating.

Residual gas. During the exhaust process, it is not possible to completely remove from the cylinder the combustion products occupying a certain volume at the pressure RG and temperature Tg. Residual gases, expanding and mixing with the incoming fresh charge, worsen the filling of the cylinders.

With an increase in the load in the diesel engine with a constant resistance of the intake system, the filling coefficient decreases slightly, which is caused by increased heating of the fresh charge with an increase in the heat supply[11,12].

\section{Conclusion}

1. The relationship between the location of the tumble IP and its profile with flow characteristics and the intensity of the rotational motion in the diesel cylinder is revealed.

2. Changing the initial profile of the tumble port made it possible to increase the air flow through the inlet ports in the entire range of the intake valve lift, as well as to avoid the adverse effect of flow stall in the zone of the valve slit.

\section{References}

1. V.P. Volkov, Dr. "Knowlidzh", 398 (2013)

2. A.S. Grebennikov, state tech. UNT, 9, 96-97 (2013)

3. S.A. Grebennikov, PGUAS, 159 - 164 (2014)

4. R.N. Safiullin, Monograph. Spbgasu, (2011)

5. R.N. Safiullin, Grigoriev V.G., Branch scientific and production magazine for employees of motor transport, 9, 52-54 (2013)

6. O.V. Lozhkin, E.Yu. Marchenko, V.N. Lozhkin, St. Petersburg. Bulletin of civil engineers Spbgasu, 5, 195-199 (2012)

7. R.N. Safiullin, V.G. Grigoriev, Yu.A. Lapshin, Proceedings of the international Academy of agrarian education, 16, 140-143 (2013)

8. M.G. Shatrov, K.A. Morozov, I.V. Alekseev, Automobile engines, 464 (2010)

9. S.K. Shestopalov, Device, maintenance and repair of passenger cars, 288 (2018)

10. A.N. Soloviev, Y.A. Ivanov, V.I. Pakhomov, I.A. Khozyaev, D.V. Rudoi, PHENMA, 51 (2018)

11. S. Kambulov, I. Bozhko, A. Olshevskaya, MATEC Web of Conferences, 224, 05022 (2018) https://doi.org/10.1051/matecconf/201822405022 